\title{
Personality-dependent inter- and intraspecific foraging competition in the invasive round goby, Neogobius melanostomus
}

Ericsson, Philip; Persson, Anders; Behrens, Jane W.; Brodin, Tomas; Hirsch, Philipp Emanuel; Sundelin, Anna; van Deurs, Mikael; von Friesen, Lisa ; Nilsson, Anders P.

Published in:

Journal of Fish Biology

Link to article, DOI:

$10.1111 / \mathrm{jfb} .14652$

Publication date:

2021

Document Version

Peer reviewed version

Link back to DTU Orbit

Citation (APA):

Ericsson, P., Persson, A., Behrens, J. W., Brodin, T., Hirsch, P. E., Sundelin, A., van Deurs, M., von Friesen, L., \& Nilsson, A. P. (2021). Personality-dependent inter- and intraspecific foraging competition in the invasive round goby, Neogobius melanostomus. Journal of Fish Biology, 98(5), 1234-1241. https://doi.org/10.1111/jfb.14652

\section{General rights}

Copyright and moral rights for the publications made accessible in the public portal are retained by the authors and/or other copyright owners and it is a condition of accessing publications that users recognise and abide by the legal requirements associated with these rights.

- Users may download and print one copy of any publication from the public portal for the purpose of private study or research.

- You may not further distribute the material or use it for any profit-making activity or commercial gain

- You may freely distribute the URL identifying the publication in the public portal 


\section{Personality-dependent inter- and intraspecific foraging competition in the invasive round goby, Neogobius melanostomus}

Ericsson, Philip ${ }^{1 *}$, Persson, Anders ${ }^{1}$, Behrens, Jane W. ${ }^{2}$, Brodin, Tomas ${ }^{3}$, Hirsch, Philipp Emanuel ${ }^{4}$, Sundelin, Anna ${ }^{5}$, van Deurs, Mikael², von Friesen, Lisa W. ${ }^{1,6}$, Nilsson, P. Anders ${ }^{1,7}$

1. Department of Biology - Aquatic Ecology, Lund University, Naturvetarvägen 6A, Lund 22362, Sweden.

2. National Institute of Aquatic Resources, DTU Aqua, Technical University of Denmark , Kemitorvet, Building 202, 2800 Kgs. Lyngby, Denmark.

3. Department of Wildlife, Fish, and Environmental Studies, Swedish University of Agricultural Sciences (SLU) - Umeå 90183, Sweden.

4. Program Man-Society-Environment, Department of Environmental Sciences, University of Basel, Vesalgasse 1, Basel CH-4051, Switzerland.

5. Department of Chemistry, Umeå University, Kemihuset, Umeå 90187, Sweden.

6. Current Address: Marine Biological Section, University of Copenhagen. Strandpromenaden 5, DK-3000 Helsingør, Denmark.

7. Department of Environmental and Life Sciences - Biology, Karlstad University, SE-651 88, Karlstad, Sweden.

* Corresponding author:

Email: philip.steven.ericsson@gmail.com

Phone: +1 (408) 761-8248

This article has been accepted for publication and undergone full peer review but has not been through the copyediting, typesetting, pagination and proofreading process which may lead to differences between this version and the Version of Record. Please cite this article as doi: $10.1111 / \mathrm{jfb} .14652$

This article is protected by copyright. All rights reserved. 


\begin{abstract}
This study examines the impact of boldness on foraging competition of the highly invasive round goby Neogobius melanostomus Pallas 1815. Individual risk tolerance, or boldness, was measured as the time to resume movement after a simulated predation strike. Fish that resumed movement faster were categorized as "bold”, fish that took more time to resume movement were categorized as "shy", and those who fell in between these two categories were determined to have "intermediate” boldness. Competitive impacts of boldness in $N$. melanostomus were determined in a laboratory foraging experiment in which interspecific (juvenile Atlantic cod Gadus morhua Linnaeus 1758) and intraspecific (intermediate $N$. melanostomus) individuals were exposed to either bold or shy N. melanostomus competitors. G. morhua consumed fewer prey when competing with bold $N$. melanostomus than when competing with shy $N$. melanostomus, whereas intermediately bold $N$. melanostomus foraging was not affected by competitor boldness. Bold and shy N. melanostomus consumed similar amounts of prey, and the number of interactions between paired fish did not vary depending on the personality of $N$. melanostomus individuals. Hence, intraspecific foraging competition was not found to be personality dependent. This study provides evidence that individual differences in boldness can mediate competitive interactions in N. melanostomus, however results also show that competition is also governed by other mechanisms which require further study.
\end{abstract}

\title{
Introduction
}

Invasions of non-native species are currently one of the largest drivers of biodiversity loss worldwide (Jackson et al., 2017), and expansions of such species are known to generate 
severe economic and environmental harm within native systems (David et al., 2017).

Recent studies of animal personality show that consistent inter-individual differences in a number of personality traits generate important fitness consequences across a wide range of life history processes (Adriaenssens and Johnsson, 2011; Sih et al., 2012; Mittelbach et al., 2014; Merrick and Koprowski, 2017). One such personality trait, boldness or the risk tolerance of an individual (Thorlacius et al., 2015), is known to influence the success of invasive species at different stages of the invasion process (transport, introduction, establishment, and spread) (Chapple et al., 2012). As non-native species introductions become more common, the need to understand how animal personality affects interactions between invaders and native species has become apparent for biologists, managers and policy makers (Copp et al., 2005).

Considered one of Europe’s top 100 worst invasive species (Hirsch et al., 2016a), the round goby Neogobius melanostomus Pallas 1814 has invaded much of the Baltic Sea, central Europe, as well as the Laurentian Great Lakes region of North America since the early 1990's (Kornis et al., 2012). Recently, N. melanostomus has been used as a model species to demonstrate how individuals at invasion fronts differ from those in established populations across a variety of traits. In addition to differences in condition, age, density, age-at-maturity, predator pressure, sex ratios, size, and even trophic position (Gutowsky and Fox, 2011; Gutowsky and Fox, 2012; Brownscombe and Fox, 2013; Brandner et al., 2013; Azour et al., 2015; Brandner et al., 2018), N. melanostomus populations exhibit behavioural differences, where individuals along invasion fronts are more aggressive, active, and bold than individuals from established populations (Groen et al., 2012, Myles- 
Gonzalez et al., 2015). The higher proportion of bold N. melanostomus found along invasion fronts could be a key driver of the invasion process for this species. In fact, these observed population differences have already been suggested to facilitate further spread, as Myles-Gonzalez et al. (2015) showed that N. melanostomus at an invasion front were bolder and dispersed sooner and farther in laboratory experiments than did individuals from an established population. However, while activity and exploratory behaviours are important metrics for predicting potential population spread (Sih et al., 2004; Cote et al., 2010), they alone cannot explain how invasions of $N$. melanostomus often lead to the rapid extirpation of native species (Janssen and Jude, 2001; Karlson et al., 2007; Brandner et al., 2013; Brandner et al., 2018, but see Kornis et al., 2013; Janáč et al., 2016).

Boldness is known to influence invasion success (Chapple et al., 2012), and behavioural differences along this axis are known to influence foraging ability (Wilson et al., 1994; Sih et al., 2004; Réale et al., 2007; Mittelbach et al., 2014), with bolder individuals utilizing prey patches faster than shy individuals (Ioannou et al., 2008) and consuming prey at faster rates than both heterospecific and shy conspecific competitors (Webster et al., 2009). Therefore, there is a timely need to study the role that personality plays in governing competitive interactions in $N$. melanostomus, as it might have important implications for the invasion dynamics of bold-biased invasions fronts such as those noted in Myles-Gonzalez et al. (2015). For example, if boldness is positively correlated to foraging rate in $N$. melanostomus, invasion fronts might exert a higher per capita competitive pressure on native species than would be expected without consideration of 
any personality-mediated differences. Ultimately, a concentration of more competitive invaders in areas of ongoing invasion could facilitate the further spread and establishment of $N$. melanostomus in non-native environments by making the invasion front overall more competitive in the interaction with the native recipient community.

To this end, we hypothesize that boldness mediates the inter- and intraspecific competitive ability of individual $N$. melanostomus. In order to test this hypothesis we compared the difference in competitive ability (defined as the number of prey items eaten) of focal N. melanostomus and juvenile Atlantic cod Gadus morhua Linnaeus 1758 individuals when competing with either bold or shy N. melanostomus. Juvenile G. morhua were used as competitors in this study because they co-occur with $N$. melanostomus in coastal areas of the western Baltic Sea (Azour et al., 2015; Carl et al., 2016) and share prey species. For example, when studying the diet of juvenile Baltic cod (15-25cm total length) during summer, Almqvist et al (2010) found up to $44.5 \%$ of the diet consisted of Crangon crangon Linnaeus 1758 shrimp, and as benthic crustaceans are generally a preferred food item of both species in the Baltic (Gruszka and Więcaszek, 2011; Kornis, 2012; Azour et al., 2015), this places the two fish species in competition for food. Additionally, because the round goby is a highly aggressive species (Dubs and Corkum, 1996), and inter- and intraspecific behavioural interactions are capable of generating interference competition, which in turn can affect individual prey consumption (e.g. Soluk and Collins, 1988; Nakayama and Fuiman, 2010) we include analyses of agonistic behaviours to help explain differences in competitive abilities. We predict that bold N. melanostomus will, via consumption and aggressive interactions (e.g. dominance 
displays and physical contact), reduce the amount of prey their competitors consume to a greater extent than would shy $N$. melanostomus.

\section{Materials and methods}

\section{Ethical Statement}

All husbandry and experimental use of animal subjects in this study were performed in accordance to the national guidelines set by the Danish Animal Ethics Committee for the care and use of laboratory animals.

Individual N. melanostomus were collected with fyke nets on the $3^{\text {rd }}$ of April 2017 in Guldborgsund, Denmark, western Baltic Sea. The sex of each fish was determined on site through examination of the urogenital papilla (Marsden et al., 1997). In order to avoid any potential gender-mediated differences in personality, only males $(\mathrm{N}=182)$ were retained for use in this study. The fish were then transported to DTU Aqua in Kongens Lyngby, Denmark, to a facility approved and certified for fish holding and experimentation by the Danish Ministry of Food and Environment of Denmark, Danish Veterinary and Food Administration. There, fish were kept in five $1500 \mathrm{~L}$ aerated tanks with fine-grained gravel substrate, artificial seagrass, and PVC tubes (diameter $7.5 \mathrm{~cm}$ ) for shelter and enrichment. Water was continuously exchanged through a recirculating flow-through system which was held at a constant $10 \pm 1^{\circ} \mathrm{C}$ and $18 \mathrm{PSU}$ (comparable to the bottom water at the location of capture). The light:dark cycle followed the natural seasonal cycle that changed from 13:11 to 16:8 during the course of the study. Fish were 
fed with defrosted shrimp ad lib every three days. On the $10^{\text {th }}$ of April 2017, PIT-tags (Passive Integrated Transponder, $12 \mathrm{~mm}, 0.1 \mathrm{~g}$, Oregon RFID) were inserted into the body cavity of each individual to allow individual identification during the trial period. No injection-associated mortality occurred. Fish were observed twice daily and humane endpoints were used, i.e. fish that showed signs of suffering or distress (ceasing of feeding, loss of equilibrium, increased ventilation frequency, and lack of normal movement and social interactions) were humanely sacrificed by a sharp blow to the head with a priest.

\section{Boldness}

One hundred and eighty two N. melanostomus individuals were used in the boldness assay (length range: 11 - $17.5 \mathrm{~cm}$ total length (TL), average length: $14.2 \mathrm{~cm} \mathrm{TL}$ ). Individual fish were placed into glass aquaria $(60 \times 30 \times 35 \mathrm{~cm}$, width $\times$ depth $\times$ height $)$ filled with $27 \mathrm{~L}$ of water along with $400 \mathrm{~mL}$ of water from the holding tanks to provide familiar chemical cues for the fish. Fish were left to acclimatize for five minutes before the start of each trial. Curtains were used to isolate each experimental area, and cardboard sheets were placed between aquaria in order to minimize stress, disturbance, and visual interactions between fish. Also, observers watched the trials from a distance in order to further minimize the disturbances experienced by the fish.

Individual risk tolerance, hereafter referred to as boldness, was analyzed according to Thorlacius et al. (2015) as the latency of an individual to resume movement after a simulated predator strike. To test this, a weight attached to a fishing line was released into 
the middle of each aquarium, penetrating the water surface by $5 \mathrm{~cm}$ within two body lengths of the fish (fish position could be viewed from distance), and was then retracted after 1 second to simulate an attempted predation strike by a bird. This technique was chosen because avian species such as grey herons Ardea cinerea Linnaeus 1758 and cormorants Phalacrocorax carbo Linnaeus 1758 are common predators of $N$. melanostomus in the shallow water areas of the Baltic (Corkum et al., 2004; Jakubas 2004, Oestewind el al., 2017). The simulated strikes and the following 30 minutes were video recorded from above (SONY, Handycam, HDR-CX405). Once the boldness scores were obtained, intermediate $N$. melanostomus individuals were housed separately from bold and shy N. melanostomus individuals for the remainder of the experimental period. The water in the experimental arenas was changed daily. After a simulated strike occurred, $N$. melanostomus either immediately stopped in place, or swam away from the strike, before stopping for a period of immobility (i.e. freezing). Following Thorlacius et al. (2015) and Hirsch et al. (2016b), the time to resume movement after this freezing was used to determine the boldness for each individual, with shorter times indicating bolder fish. These data were converted to seconds, then $\log _{10}$ transformed and subtracted from the $\log _{10}$ of the time limit for the assay (30 minutes $=1,800$ seconds) in order to generate increasing scores with increasing levels of boldness. One individual took longer than 1,800 seconds to resume movement after a simulated predation strike and was assigned the ceiling time of 1,800 seconds. To determine the consistency and repeatability of boldness scores for N. melanostomus, a second round of assays was run one month later using a subset of fish (26 bold, 26 shy, and 10 intermediate). 


\section{Competition}

The competition experiment was run between the $11^{\text {th }}$ and the $23^{\text {rd }}$ of July 2017. G. morhua used in this experiment were caught with fyke nets on the $25^{\text {th }}$ of April 2017 in southern Øresund and brought to DTU and tagged following the protocol used for $N$. melanostomus individuals. Experimental trials occurred between pairs of fish, consisting of either juvenile $G$. morhua $(\mathrm{N}=10$, size range: 16 - $21 \mathrm{~cm}$ TL, average length: $19.2 \mathrm{~cm}$ TL) or “intermediate personality” $N$. melanostomus $(\mathrm{N}=10$, size range: $14-16 \mathrm{~cm}$ TL, average length: $14.7 \mathrm{~cm}$ TL), henceforth both referred to as "focal” fish, and either bold ( $N=20$, size range: $11-16.5 \mathrm{~cm}$ TL, average length: $14.6 \mathrm{~cm}$ TL) or shy $N$. melanostomus ( $\mathrm{N}=20$, size range: 13 - $18 \mathrm{~cm}$ TL, average length: $15.0 \mathrm{~cm} \mathrm{TL}$ ), henceforth referred to as "treatment” fish. "Bold” N. melanostomus refers to the twenty fish with the highest boldness scores as determined in the boldness assays, while "shy" $N$. melanostomus refers to the twenty with the lowest scores, and focal N. melanostomus refers to those with an intermediate boldness score. These combinations resulted in both inter- and intraspecific pairs of fish, where focal G. morhua and focal N. melanostomus individuals were each exposed to both a bold and a shy treatment $N$. melanostomus in a randomized order, while treatment fish were not used more than once. Trials were run every fourth day, and fish were fed to satiation after each trial. All individuals used in competition experiments were sacrificed at the end of the trials. Remaining individuals used for boldness scores but not in competition experiments were kept in holding tanks and fed every second day for later use in other experiments. 
Experimental arenas consisted of glass aquaria $(60 \times 30 \times 35 \mathrm{~cm}$, width $\times$ depth $\times$ height $)$, which were covered on the bottom and three sides with grey waterproof paper to reduce glare and the amount of stress experienced by the fish. As in the boldness assays, the experimental area was kept behind a curtain in order to minimize visual disturbances during the trials. Focal fish were paired with treatment fish in such a way as to reduce the size difference between individuals as much as possible (heterospecific pairs: $0-7.5 \mathrm{~cm}$ length difference, average length difference: $4.4 \mathrm{~cm}, 22.6 \% \mathrm{TL}$ ) (conspecific pairs: 0 $3.5 \mathrm{~cm}$ length difference, average length difference: $1.1 \mathrm{~cm}, 7.82 \% \mathrm{TL}$ ), placed into aquaria in a random order, and allowed to acclimatize for one hour prior to the start of each trial. After the acclimatization period, 30 live shrimp (Palaemon spp.) were added to each aquarium and the fish pairs were then allowed to feed for 45 minutes. Shrimp were caught with hand nets in the shallow rocky near-shore area of Charlottenlund, Denmark, and were chosen as prey as they are a naturally occurring food item for both $N$. melanostomus and G. morhua in the Baltic Sea (Gruszka and Więcaszek, 2011; Kornis, 2012). After each trial ended, fish were removed and returned to their respective holding tanks, and the number of remaining shrimp were counted. Each trial was recorded using SONY, Handycam (HDR-CX405). Video recordings were manually analyzed for the number of prey items eaten by both focal and treatment fish, along with total number of aggressive interactions that occurred between pairs of fish in each trial. Specifically, bites, fin displays, charges, and chases were recorded. 
Statistical analyses

All statistical analyses and data visualization were run in R (R Core Team, 2017). Data were visualized using packages ggplot2 (Wickham, 2009), plyr (Wickham, 2011) and reshape2 (Wickham, 2007). P-values were considered significant at the 0.05 level.

\section{Personality}

Possible effects of $N$. melanostomus body size (TL) on boldness score for individuals included in competition experiments were evaluated with Spearman’s rank correlation. For fish with repeated personality assays, the repeatability of boldness score measurements were estimated using the intraclass correlation coefficient (ICC) in the package irr (Gamer et al., 2012), and Spearman’s rank correlation was used to estimate the consistency of individual boldness scores between the two personality assays, evaluated according to Thorlacius et al. (2015) and Bell et al. (2009).

\section{Competition and interactions}

Generalized linear mixed-effects models were used to analyze the dependent variables 'focal fish consumption', 'treatment fish consumption', and 'total interactions' (the total number of interactions that occurred in each trial). 'Focal species' (G. morhua or intermediate $N$. melanostomus), and 'treatment fish personality' (bold or shy $N$. melanostomus) were included as factors in these models, as was their interaction term 'focal species' × 'treatment fish personality'. Also included in the models were covariates for both focal fish length and treatment fish length, and the random intercept ‘focal fish individual I.D.' nested within 'focal species’ to account for the repeated 
measures made on each focal fish. Model assumptions were checked and confirmed using the package "DHARMa” (Hartig, 2020). However it was found that the model for 'total interactions' suffered from overdispersion and was therefore re-run assuming the negative-binomial distribution using the package "glmmTMB” (Brooks et al., 2017). Models for 'focal fish consumption' and 'treatment fish consumption' were running using the glmer function in package "Ime4" (Bates et al., 2015).

\section{Results}

In the personality assays, time to resume movement after freezing ranged from 1.79 seconds to over 30 minutes (average time spent frozen: 3 min $42 \mathrm{sec}$ ) for the $182 \mathrm{~N}$. melanostomus used. Boldness estimates (latency to move) were not correlated with fish size (TL) (Spearman's $\rho=0.104, P=0.47$ ). For the 62 fish assayed in the second trial, latency to move ranged from 1.84 seconds to over 17 minutes (average time: 2 min 42 sec). Both the ICC and Spearman's rank correlation analyses were significant, showing that boldness of $N$. melanostomus was both consistent and repeatable through the onemonth period between assays (Repeatability: F61, $62=2.68, P<0.001$, ICC $=0.457$, (0.457 $>0.37$ as reported as mean for repeatable behaviours in Bell et al. 2009) $95 \%$ CI = 0.269 - 0.655; Consistency: Spearman's $\rho=0.48, P<0.001$, Figure 1).

Prey were consumed in 36 out of the 40 competition trials. Total prey consumption ranged from 0 to 22 shrimp $(6.73 \pm 5.62$, mean \pm SD) eaten per trial. Neither focal fish species nor the length difference between individuals had significant effects on the amount of prey consumed by focal fish. However, both treatment fish personality and the 
interaction term between treatment fish personality and focal fish species were significant (Table 1), such that prey consumption for focal G. morhua was significantly lower when paired with bold $N$. melanostomus, while focal $N$. melanostomus consumed similar amounts of prey regardless of the personality of the treatment fish (Figure 2a).

The amount of prey consumed by treatment fish did not depend on focal fish species, the individual's own personality type, the interaction term between species and treatment fish personality, or focal fish length (Table 1, Figure 2b). Prey consumed by treatment fish was however affected by treatment fish length (Table 1), where larger treatment fish consumed more prey than smaller treatment fish.

While more interactions appeared to occur in intraspecific trials than in the interspecific trials (Figure 2c), none of the factors had a significant effect on the total number of interactions that occurred in each trial (Table 1). .

\section{Discussion}

This study evaluates competitor-specific and personality-dependent (i.e. boldness, risk tolerance) foraging competition effects of $N$. melanostomus. Focal G. morhua consumed fewer prey when competing with bold treatment fish than when competing with shy treatment fish. This was however not the pattern for intraspecific competition, as focal $N$. melanostomus consumed comparable amounts of prey in trials with both treatment types. The study further suggests that boldness in N. melanostomus is not correlated to prey consumption or aggressive behaviour. 
The fact that individual G. morhua consumed fewer prey while competing with bold treatment fish is evidence of a boldness-mediated control on interspecific competition in N. melanostomus. However, the mechanism of that control remains unclear, as neither the number of prey consumed by treatment fish, nor the number of interactions in each trial depended on the personality of treatment fish. Therefore, it is possible that other traits linked to boldness in N. melanostomus mediate G. morhua prey consumption. One potential trait that could mediate interspecific interactions in this species is metabolic rate. Recently, Behrens et al. (2020) found that bold N. melanostomus individuals (from the same population that was used in the present study) had higher standard metabolic rates than shy $N$. melanostomus, suggesting that bold individuals require more resources in order to maintain homeostasis than shy individuals. Additionally, Myles-Gonzales et al. (2015) found that the resting metabolic rates for $N$. melanostomus from an active invasion front were significantly higher than those for individuals from an established population. It therefore seems that an open avenue of future study would be to explicitly examine how metabolic rate relates to competitive interactions for this species, and to determine if metabolic rate drives phenotypic traits, or if other characteristics of the individual drive metabolic rate.

Analysis of prey consumption by treatment fish show that competitive differences between bold and shy $N$. melanostomus are not due to differences in the number of prey items consumed by each personality type. Several previous studies of competition in $N$. melanostomus have shown that the competitive success of this species is often a result of 
high levels of aggressive and antagonistic behaviours towards competitors (e.g. Dubs and Corkum, 1996; Jansen and Jude, 2001; Balshine et al., 2005; Bergstrom and Mensinger 2009; Church et al., 2017; Leino and Mensinger, 2017). While boldness and aggression are often linked within individuals, with bolder individuals being more aggressive than shy individuals (Sih et al., 2004; Biro and Stamps 2008), Groen et al. (2012) detected no association between boldness and aggression at the population level for $N$. melanostomus in either invasion-front individuals or in individuals from established populations in a laboratory experiment. Results from the present study also show no association between boldness and aggressive interactions, giving further indication that these two behaviours are not linked in this species. Furthermore, there were fewer aggressive interactions in heterospecific trials than in conspecific trials. This puts into question the role that aggression plays during the invasion process, and this topic deserves continued attention in future studies examining invasion dynamics for this species.

The absence of boldness-dependent effects on intraspecific foraging competition indicates that there are other mechanisms mediating behaviour in this species. $N$. melanostomus aggregate in high-density populations (Marsden et al., 1997; Kornis et al., 2012), nest in close proximity to each other (Wickett and Corkum, 1998), and prefer to associate with other $N$. melanostomus individuals rather than remaining solitary (Capelle et al., 2015), despite being highly aggressive (Dubs and Corkum, 1996). A recent study by Borcherding et al. (2019) also showed that N. melanostomus maintained high overall consumption rates at high population densities, confirming the notion that interspecific competition does not put strong limits on prey consumption in this species. Collectively, 
this suggests that $N$. melanostomus is highly tolerant of conspecifics, and that this tolerance plays an important role in defining the dynamics of invasion in this species.

The study design aimed to size match the paired individuals in competition trials, and neither focal fish length nor treatment fish length had effects on focal fish consumption and total amount of interactions in dyads. However, treatment fish length did affect treatment fish consumption, with larger $N$. melanostomus eating more prey than small $N$. melanostomus. This influence of body size on consumption by treatment fish agrees with the findings of Groen et al. (2012), who concluded that body size is a more important factor than aggression or boldness for determining the outcome of competitive interactions in $N$. melanostomus.

Although the personality-dependent foraging competition in $N$. melanostomus does not follow our intraspecific prediction that bold individuals forage more intensely, it has possible implications for the species' invasiveness and establishment in new environments. To fully understand the effects of $N$. melanostomus invasion, it is important that future steps elucidate the long-term consequences of competitive effects and differences between personality types, as these patterns may change both temporally and spatially. It should be noted that this study was restricted to males, why effects of possible personality types in females also deserve attention. Additionally, effective invasive species management and mitigation strategies are reliant on detailed and holistic knowledge of community-level processes. Therefore, future work should also include field studies that track native community responses to real-time $N$. melanostomus 
invasions. If invasions are dependent on dispersal potential or how risk-adverse an individual is, trapping strategies could be developed to selectively block or remove phenotypes more likely to successfully establish in a novel environment. If habitat preference is dependent on metabolic performance, then it is possible that restoration strategies might be focused in such a way to minimize invasion potential for targeted habitats. Studying how inter-individual differences in personality affect life history processes will continue to provide new angles from which to examine the dynamics of species invasions. We believe these insights will lead to the development of novel solutions to one of the Anthropocene's main threats to biodiversity, invasive species.

\section{Acknowledgements}

This work resulted from funding from The Gyllenstiernska Krapperup’s Foundation and the BONUS INSPIRE project supported by BONUS (Art 185), funded jointly by the EU and the Swedish research council Formas.

\section{Contributions}

Original idea and concept by P. A. N., A. P., J. B., T. B., P. H., and M. D. Personality assays run by L. W. vF., A. S., J. B., and M. D. Competition experiment run by P. E. and L. W. vF. Data analysis by P. E., P. A. N., A. P, and T. B. Interpretation of results by P. E., P. A. N., and A. P. Manuscript writing lead by P. E. with contribution from all authors.

\section{References}

This article is protected by copyright. All rights reserved. 
Adriaenssens, B. and Johnsson, J. I. 2011. Shy trout grow faster: Exploring links between personality and fitness-related traits in the wild. - Behav. Ecol. 22: 135-143.

Almqvist, G. et al. 2010. Has the invasive round goby caused new links in Baltic food webs? - Environ. Biol. Fishes. 89: 79-93. doi:10.1007/s10641-010-9692-z.

Azour, F. et al. 2015. Invasion rate and population characteristics of the round goby Neogobius melanostomus: Effects of density and invasion history. - Aquat. Biol. 24: 4152.

Balshine, S. et al. 2005. Competitive interactions between round gobies and logperch. - J. Great Lakes Res. 31: 68-77.

Bates, D. et al. 2014. Fitting Linear Mixed-Effects Models using lme4. - J. Stat. Softw. 67: 1-48.

Bell, A.M. et al. 2009. The repeatability of behaviour: a meta-analysis. Animal Behaviour 77: 771-783.

Bergstrom, M. A. and Mensinger, A. F. 2009. Interspecific Resource Competition between the Invasive Round Goby and Three Native Species: Logperch, Slimy Sculpin, and Spoonhead Sculpin. - Trans. Am. Fish. Soc. 138: 1009-1017.

Behrens, J. W. et al. 2020. Personality- and size-related metabolic performance in invasive round goby (Neogobius melanostomus). - Physiol. Behav. 215: 112777

Biro, P. A. and Stamps, J. A. 2008. Are animal personality traits linked to life-history productivity? - Trends Ecol. Evol. 23: 361-368.

Borcherding, J. et al. 2019. Competition fluctuates across years and seasons in a 6species-fish community: empirical evidence from the field. - Rev. Fish Biol. Fisher. 29: 589-604. doi:10.1007/s11160-019-09567-x 
Brandner, J. et al. 2013. Bigger Is Better: Characteristics of Round Gobies Forming an Invasion Front in the Danube River. - PLoS ONE. 8: e73036.

Brandner, J. et al. 2018. Invasion strategies in round goby (Neogobius melanostomus): Is bigger really better? - PLoS ONE. 13: e0190777.

Brooks, M. E., et al. 2017. glmmTMB Balances Speed and Flexibility Among Packages for Zero-inflated Generalized Linear Mixed Modeling. The R Journal. 9: 378-400.

Brownscombe, J. W. and Fox, M. G. 2013. Living at the edge of the front; reduced predation risk to invasive round goby in a Great Lakes tributary. - Hydrobiologia. 707: 199-208.

Capelle, P. M. et al. 2015. Aggression and sociality: Conflicting or complementary traits of a successful invader? - Behavior. 152: 127-146.

Carl, H. et al. 2016. Statusrapport vedr. udbredelsen af ikke-hjemmehørende fiskearter i danske farvande (2016). pp 35.

Chapple, D. G. et al. 2012. Can behavioral and personality traits influence the success of unintentional species introductions? - Trends Ecol. Evol. 27: 57-62.

Church, K. et al. 2017. Aggressive interactions between two invasive species: the round goby (Neogobius melanostomus) and the spinycheek crayfish (Orconectes limosus). Biol. Invasions. 19: 425-441.

Copp, G.H. et al. 2005. To be, or not to be, a non-native freshwater fish? - J. Appl. Ichthyol. 21: 242-262.

Corkum, L. D. et al. 2004. The round goby, Neogobius melanostomus, a fish invader on both sides of the Atlantic Ocean. - Biol. Invasions. 6: 173-181. 
Cote, J. et al. 2010. Personality-dependent dispersal: characterization, ontogeny and consequences for spatially structured populations. - Philos. Trans. R. Soc. B Biol. Sci. 365: 4065-4076.

David, P. et al. 2017. Impacts of Invasive Species on Food Webs: A Review of Empirical Data. - Adv. Ecol. Res. 56: 1-60.

Dubs, D. O. L. and Corkum, L. D. 1996. Behavioral interactions between round gobies (Neogobius melanostomus) and Mottled Sculpins (Cottus bairdi). - J. Great Lakes Res. 22: 838-844.

Fox, J. and Weisberg, S. 2011. An \{R\} Companion to Applied Regression, Second Edition. Thousand Oaks CA: Sage.

Gamer, M. et al. 2012. irr: Various Coefficients of Interrater Reliability and Agreement. R package version 0.84 .

Groen, M. et al. 2012. Is there a role for aggression in round goby invasion fronts? Behaviour. 149: 685-703.

Gruszka, P. and Więcaszek, B. 2011. Palaemon elegans Rathke, 1837 in the food of Baltic cod (Gadus morhua callarias L., 1758) from the Gulf of Gdańsk. - Mar. Biol. Res. 7: 100-105.

Gutowsky, L. F. G. and Fox, M. G. 2012. Intra-population variability of life-history traits and growth during range expansion of the invasive round goby, Neogobius melanostomus. - Fish. Manag. Ecol. 19: 78-88.

Gutowsky, L. F. G. and Fox, M. G. 2011. Occupation, body size and sex ratio of round goby (Neogobius melanostomus) in established and newly invaded areas of an Ontario river. - Hydrobiologia. 671: 27-37. 
Hartig, F. 2020. DHARMa: Residual Diagnostics for Hierarchical (Multi-Level / Mixed) Regression Models. R package version 0.3.3.0. https://CRAN.Rproject.org/package=DHARMa.

Hempel, M. and Thiel, R. 2015. Effects of salinity on survival, daily food intake and growth of juvenile round goby Neogobius melanostomus (Pallas, 1814) from a brackish water system. - J. Appl. Ichthyol. 31: 370-374.

Hirsch, P. E. et al. 2016a. What do we really know about the impacts of one of the 100 worst invaders in Europe? A reality check. - Ambio. 45: 267-279.

Hirsch, P. E. et al. 2016b. An approach to incorporate individual personality in modeling fish dispersal across in-stream barriers. - Ecol. Evol. 7: 720-732.

Ioannou, C. et al. 2008. Ecological consequences of the bold-shy continuum: The effect of predator boldness on prey risk. - Oecologia. 157: 177-182.

Jackson, M. C. et al. 2017. Novel and Disrupted Trophic Links Following Invasion in Freshwater Ecosystems. - Adv. Ecol. Res. 57: 55-97.

Jakubas, D. 2004. The response of the grey heron to a rapid increase of the round goby. Waterbirds 27:304-307.

Janáč, M. et al. 2016. No effect of round goby Neogobius melanostomus colonisation on young-of-the-year fish density or microhabitat use. - Biol. Invasions. 18: 2333-2347. Janssen, J. and Jude, D. J. 2001. Recruitment failure of mottled sculpin Cottus bairdi in Calumet Harbor, southern Lake Michigan, induced by the newly introduced round goby Neogobius melanostomus. - J. Great Lakes Res. 27: 319-328.

Karlson, A. M. L. et al. 2007. Indications of competition between non-indigenous round goby and native flounder in the Baltic Sea. - ICES J. Mar. Sci. 64: 479-486. 
Kornis, M. S. et al. 2012. Twenty years of invasion: A review of round goby Neogobius melanostomus biology, spread and ecological implications. - J. Fish Biol. 80: 235285.

Kornis, M. S. et al. 2013. Invasion success and impact of an invasive fish, round goby, in Great Lakes tributaries. - Divers. Distrib. 19: 184-198.

Kuznetsova, A. et al. 2017. lmerTest Package: Tests in Linear Mixed Effects Models. - J. Stat. Softw. 82: 1-26.

Leino, J. R. and Mensinger, A. F. 2017. Interspecific competition between the round goby, Neogobius melanostomus, and the logperch, Percina caprodes, in the DuluthSuperior Harbour. - Ecol. Freshw. Fish. 26: 34-41.

Marsden, J.E. et al. 1996. The Round Goby (Neogobius melanostomus): A Review of European and North American Literature. Aquatic Ecology Technical Report 96/10. Illinois Natural History Survey. Lake Michigan Biological Station, Zion, Illinois. Merrick, M. J. and Koprowski, J. L. 2017. Should we consider individual behavior differences in applied wildlife conservation studies? - Biol. Conserv. 209: 34-44.

Mittelbach, G. G. et al. 2014. Fish behavioral types and their ecological consequences. Can. J. Fish. Aquat. Sci. 71: 927-944.

Myles-Gonzalez, E. et al. 2015. To boldly go where no goby has gone before: Boldness, dispersal tendency, and metabolism at the invasion front. - Behav. Ecol. 26: 10831090.

Nakayama, S. and Fuiman, L. A. 2010. Body size and vigilance mediate asymmetric interference competition for food in fish larvae. - Behav. Ecol. 21: 708-713. 
Nash, J. C. and Varadhan, R. 2011. Unifying Optimization Algorithms to Aid Software System Users: optimx for R. - J. Stat. Softw. 43: 1-14.

Oesterwind, D. et al. 2017. Predator and prey: the role of the round goby Neogobius melanostomus in the western Baltic. - Mar. Biol. Res. 13: 188-197.

R Core Team. 2017. R: A language and environment for statistical computing. $\mathrm{R}$ Foundation for Statistical Computing, Vienna, Austria. https://www.R-project.org/. Réale, D. et al. 2007. Integrating animal temperament within ecology and evolution. Biol. Rev. 82: 291-318.

Sapota, M. R. 2004. The round goby (Neogobius melanostomus) in the Gulf of Gdánsk a species introduction into the Baltic Sea. - Hydrobiologia. 514: 219-224.

Sapota, M. R. and Skóra, K. E. 2005. Spread of alien (non-indigenous) fish species Neogobius melanostomus in the Gulf of Gdansk (south Baltic). - Biol. Invasions. 7: $157-164$.

Sih, A. et al. 2004. Behavioral syndromes: An ecological and evolutionary overview. Trends Ecol. Evol. 19: 372-378.

Sih, A. et al. 2012. Ecological implications of behavioural syndromes. - Ecol. Lett. 15: 278-289.

Soluk, D. A. and Collins, N. C. 1988. Synergistic Interactions between Fish and Stoneflies: Facilitation and Interference among Stream Predators. - Oikos. 52: 94100.

Stammler, K. L. and Corkum, L. D. 2005. Assessment of fish size on shelter choice and intraspecific interactions by round gobies Neogobius melanostomus. - Environ. Biol. Fishes 73: 117-123. 
Thorlacius, M. et al. 2015. Behavioral dependent dispersal in the invasive round goby Neogobius melanostomus depends on population age. - Curr. Zool. 61: 529-542.

Webster, M. M. et al. 2009. Individual boldness affects interspecific interactions in sticklebacks. - Behav. Ecol. Sociobiol. 63: 511-520.

Wickett, R. G. and Corkum, L. D. 1998. You Have to Get Wet: A Case Study of the Nonindigenous Great Lakes Fish, Round Goby. - Fisheries. 23: 26-27.

Wickham, H. 2007. Reshaping Data with the \pkgreshape Package. - J. Stat. Softw. 21: 1-20.

Wickham, H. 2009. ggplot2: Elegant Graphics for Data Analysis. Springer-Verlag New York.

Wickham, H. 2011. The Split-Apply-Combine Strategy for Data Analysis. - J. Stat. Softw. 40: 1-29.

Wilson, D. S. et al. 1994. Shyness and boldness in humans and other animals. - Trends Ecol. Evol. 9: 442-446. 


\section{Ethics Questionnaire for JFB}

Submitted manuscripts will only be considered if the experimental methods employed are ethically justified. Please answer all questions. If you have answered 'yes' to questions 4 to 7 , you should include an Ethics paragraph in the Methods section of your manuscript which justifies your methods used. You should complete this questionnaire based on all fishes used in your experiment. For example, if you used live fishes as prey in predation experiments, this is a lethal endpoint for the prey fish (see Questions 5 \& 6). Please read the Editorial published in JFB 68, 1-2, for full information on JFB ethics. PLEASE SUBMIT THE COMPLETED QUESTIONNAIRE WITH YOUR MANUSCRIPT ONLINE THROUGH EDITORIAL MANAGER.

Corresponding author's name: Philip Ericsson

Question 1: Were fishes collected as part of faunal surveys? YES/NO

If 'Yes', have the fishes, where feasible, been killed rapidly or returned to the wild after being held in aquaria and have procedures complied with local and or national animal welfare laws, guidelines and policies? If Yes, state these and provide suitable evidence (e.g. for the U.K. a Home Office PPL number is sufficient) that protocols have undergone an ethical review process by an institutional animal care and use (or similar) committee, a local ethics committee

No, the fish were collected specifically for the experiments reported in the submitted manuscript, and held at the animal holding facility at DTU Aqua, Lyngby. This is a fish holding facility that is approved by the Danish Ministry of Food and Environment of Denmark, Danish Veterinary and Food Administration, as a certified facility for fish holding and experimentation.

Question 2: If you have undertaken experimental work, has the care and use of experimental animals complied with local and or national animal welfare laws, guidelines and policies? YES/NO If 'Yes', state these and provide suitable evidence (e.g. for the U.K. a Home Office PPL number is sufficient), both here and in the manuscript, that protocols have undergone an ethical review process by an institutional animal care and use (or similar) committee, a local ethics committee, or by appropriately qualified scientific and lay colleagues.

Yes. According to Danish legislation, capture and handling of experimental fish do not require a permit from the national animal welfare committee. Furthermore, according to Danish legislation, standard procedures for tagging animals (e.g. earmarking of cows, PIT tagging of fish ect) do not require a permit. 
If ' $N o^{\prime}$, because these laws do not exist in your country, please state this. Alternatively, if you carried out purely observational work so ethical permission was not considered necessary please state this both here and in the manuscript.

Question 3: Were fishes killed during or at the end of your experiment (e.g. for tissue sampling)? YES/NO

If 'Yes', what method was used? Please provide details both here and in the manuscript.

Yes. Fish used in competition trials were sacrificed at the end of the experiment by quickly severing the CNS. Additionally, humane endpoints were employed during the span of the experiment where fish displaying obvious signs of suffering were sacrificed using the same method.

Question 4: Have you performed surgical procedures? YES/NO

If 'Yes', please give brief details of the surgery here. Full details should be given in the manuscript. If the procedures caused more than slight pain or distress, did you use appropriate sedation, analgesia and anaesthesia, with post-operative care? Please provide full details and justification both here and within the manuscript including type and concentration of anaesthetic.

Yes, we injected $12 \mathrm{~m}$ PIT tags into all fish used in the competition experiments. The fish were not anaesthetized, which according to Danish law (along with several other countries) is not required. If the fish in general are calm, putting a damp cloth over their head and quickly tagging them and returning them to their 'home' tank, may be less stressful than being anaesthetized, and having to recover again following anesthesia.

This article is protected by copyright. All rights reserved. 
Question 5: Did you use experimental conditions that severely distressed any fishes involved in your experiments? YES/NO

If 'Yes', state the conditions and how they can be justified. What humane endpoints were used to minimise the effects? Please provide full justification within the methods section of your manuscript.

No, moreover experimental conditions were designed in order to minimize the amount of stress experienced by the fish.

Question 6: Did any of the experimental procedures, particularly those that involve lethal endpoints (e.g. predation studies, toxicity testing), cause lasting harm to sentient fishes? YES/NO

If 'Yes', provide details both here and in the methods section of your manuscript. Normally these procedures will be considered unacceptable by JFB unless any harm caused can be justified against the benefits gained.

No, experimental procedures did not cause lasting harm to the fish.

Question 7: Did any of your procedures involve sentient, un-anaesthetised animals paralysed by chemical agents such as muscle relaxants? YES/NO

If 'Yes', provide details both here and in the methods section of your manuscript. Normally these procedures will be considered unacceptable by JFB.

No.

This article is protected by copyright. All rights reserved. 
Previous work on personality in the invasive round goby Neogobius melanostomus have focused heavily on dispersal tendencies and activity levels, but so far little attention has been paid to the influence of personality on direct competition. The current study shows how personality (specifically boldness/shyness) affects intra- and interspecific competition for $\mathrm{N}$. melanostomus and gives insight into some plausible mechanisms that have enabled this species to become such a successful invader.

This article is protected by copyright. All rights reserved. 
Figure 1. Time to resume movement after a simulated predation strike for Neogobius melanostomus Pallas 1815 for individuals in both a first ( $\mathrm{x}$-axis) and second (y-axis) personality assay.

Figure 2. A) Number of prey eaten by Gadus morhua Linnaeus 1758 and Neogobius melanostomus Pallas 1815 individuals in competition with bold (white boxes) or shy (grey boxes) N. melanostomus individuals; B) number of prey eaten by bold and shy N. melanostomus individuals in competition with G. morhua (white boxes) or "intermediate personality" $N$. melanostomus (grey boxes) individuals; and C) total number of interactions between heterospecific ( $N$. melanostomus - G. morhua) and conspecific ( $N$. melanostomus $-N$. melanostomus) pairs of fish, where white bars indicate treatments with bold $N$. melanostomus and grey bars indicate treatments with shy N. melanostomus. Error bars indicate $95 \%$ confidence intervals. 


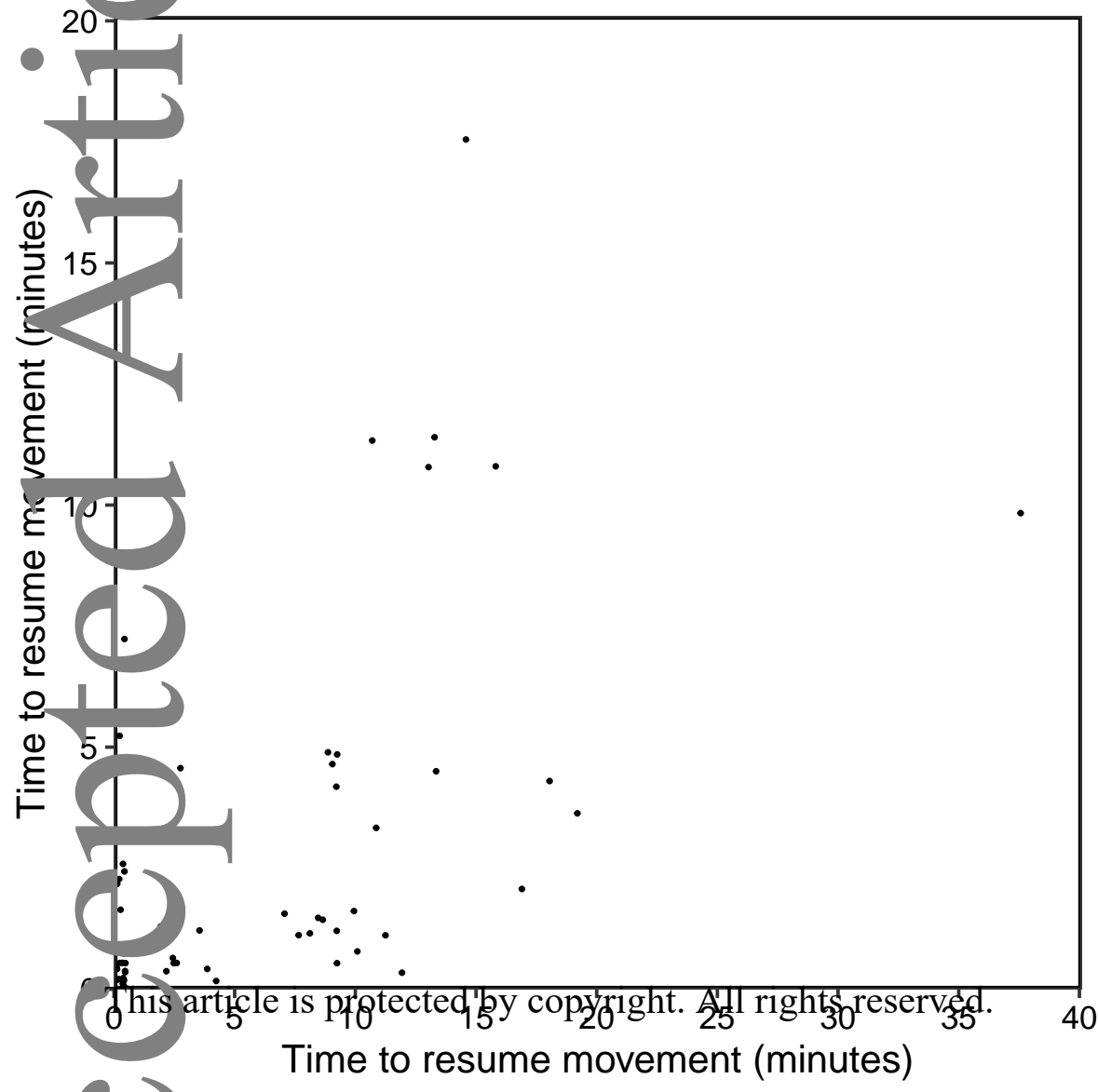




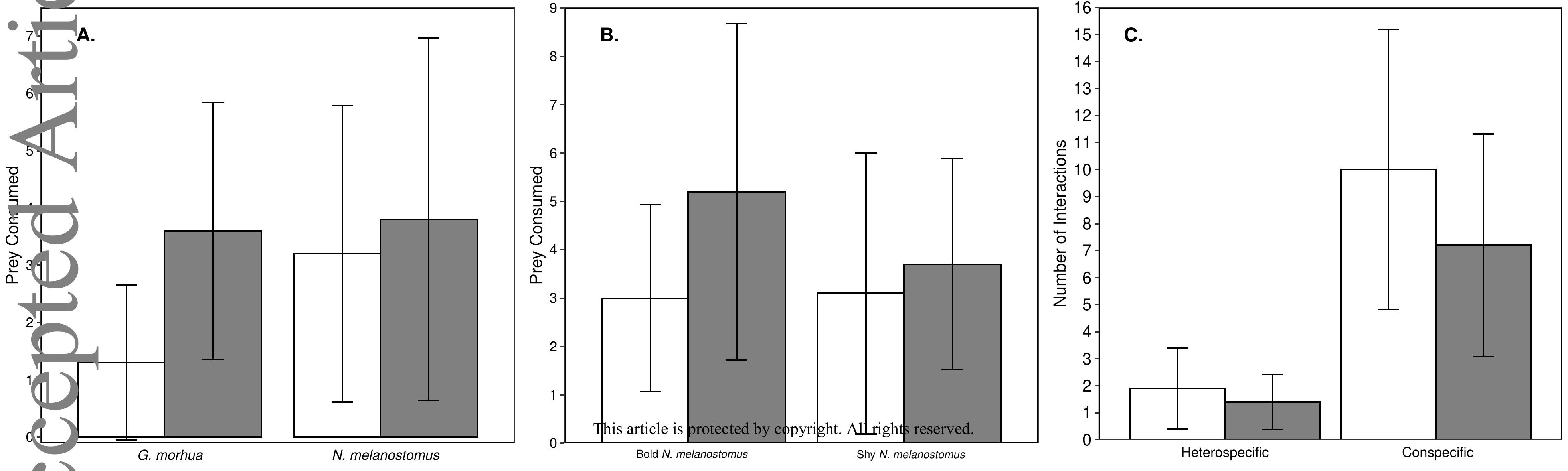

